\title{
XIX. Researches on photographic action inside discharge tubes
}

\section{Angelo Battelli}

To cite this article: Angelo Battelli (1897) XIX. Researches on photographic action inside discharge tubes, Philosophical Magazine Series 5, 43:261, 133-135, DOI: 10.1080/14786449708620970

To link to this article: http://dx.doi.org/10.1080/14786449708620970

曲 Published online: 08 May 2009.

Submit your article to this journal $\sqsubset \pi$

Џ Article views: 3

Q View related articles $\asymp$ 
XIX. Researches on Photographic Action inside Discharge Tubes. By ANGELo BatTeldi*.

THE great similarity that exists between the action of the $x$-rays and the action that Herr Lenard, of Hungary, obtained with tubes baving one end closed with aluminium, induces us to suppose that the kathodic rays may directly produce within the tube both photographic action and electric dispersion.

To demonstrate the photographic action a cylindrical tube was used, having sealed to it near the middle a wide glass stem (C). Through the said glass stem was introduced into the tube a photographic film, surrounded by black paper, and placed on a metallic cylinder. Four different designs of wire were fixed longitudinally on the roll of black paper, upon four lines placer at a distance of $90^{\circ}$ the one from the other, so that one design faced the kathode or negative pole, another the anode or positive pole, and the other two designs the lateral walls of the tube.

In all the experiments made a very strong impression occurred on the face turned to the kathode, and a very slight one on the other faces of the film.

We might, however, explain the fact by assuming that the kathodic rays striking on the sheet of black paper made it apt to emit the $x$-rays with greater efficiency than the end of the tube, which is more distant from the kathode and the photographic film than the black paper.

To meet this objection I tried, first of all, placing two similar sensitive cylinders the one inside the tube, the other outside it, in order to have the two anterior faces of the films in very nearly the same condition, the first in relation to the end of the tube, the second in relation to the black paper; that is, I placed two of the cylinders before-mentioned in connexion with the end of the tube exposed to the kathodic rays, but the one inside it and the other outside.

It resulted that the face of the film turned to the kathode remained strongly acted on after a very short exposure, while the exterior film showed a very feeble impression.

To render the condition of the inner film still more similar to that of the exterior one, I constructed a double tube divided by the means of a glass partition into two longitudinal compartnents. The first compartment contained the anode and kathode, and on the two faces of the glass partition were 
set the two cylinders surrounded by black paper, the one in the first compartment the other in the second respectively. The two compartments were meanwhile exhausted by the same pump. The results were the same as in the preceding experiments. But to place beyond any doubt that the photographic action was due to the paper struck by the kathodic rays, I fixed on the paper surrounding the cylinders some glass threads of various thickness and quality.

As glass is known to emit the $x$-rays as well as paper when it is struck by the kathode-rays, it follows that the said threads should appear as lines of greater impression on the photographic plate.

On the contrary, in all the experiments I have conducted I always obtained on the film well-marked shadows of the glass threads. They are little less perceptible than those of iron or copper wires.

Thin glass plates also, about $1 / 10$ of a millimetre thick, cast their shadow on the photographic film.

There remains still a remarkable difference observed by Röntgen between the $x$-rays and the katbodic rays, namely, that the $x$-rays are not deflected by the nagnet, while the kathodic rays are.

Also on this point I have had recourse to experiment.

I constructed a tube of a spherical form in which the kathode and anode were placed within two tubes situated along the same diameter of the sphere. A cylinder surrounded by a photographic film, protected by black paper, was introduced into the sphere through the stem and suspended there within the upper hemisphere. A strong electromagnet was fixed on the sides before the lower hemisphere, so that the kathodic rays were strongly deflected. From what the eye could perceive they touched slightly the inferior brim of the sensitive cylinder.

The different experiments conducted all gave a strong action on the film on the face turned towards the kathode, and a less strong one on the face turned to the fluorescent disk struck by the kathodic rays, and no action at all on the rest of the surface.

We must then conclude that the rays which inside the tube are capable of photographic action are not (at least a part of them) deflected by the magnet.

Then I introduced into the spherical tube a sensitive cylinder which occupied the whole height of the sphere, and applied the magnet to the same place as before. The films when developed showed that the photographic action was much more intense in the region to which the kathodic rays 
had been attracted. Hence, amongst the rays deflected by the magnet there are some endowed with photographic action.

In addition, I tried to investigate how the photographic action inside the tube varies with the variation of the rarefaction.

The result of the experiments proved that such action takes place even when all the conditions that we judge to be ordinarily connected with the production of the kathodic rays are not satisfied.

Beginning with the internal pressure of $3 / 10$ of a millimetre, at which the tube is filled with a white-violet light that ends at the two electrodes, where from time to time little sparks are visible, the photographic action increases at first rapidly with the rarefaction, and then, from $1 / 100$ of a millimetre onwards, much more slowly.

Finally, to eliminate the doubt that the photographic action inside the tube was due to an electric effluvium between the paper and the metallic cylinder* ${ }^{*}$ I surrounded the latter with a thimble of brass-wire gauze connected to a copper wire dipping into the mercury of the pump, which, in its turn, was put in connexion with the ground.

All the films showed on development a darkening of the same order of intensity as that which was produced withont the metallic screen, while the shadow of the whole gauze remained well delineated on the film itself.

While these experiments point to facts notewortly in themselves, they lead us to conchude that Röntgen's rays are already existing inside the tube as well as those studied by Lenard. The ones would pass better than the others through the walls. Hence they alone would pass out if the tube were of a somewhat thick glass.

\section{The Multiple Spectra of Gases. \\ By John Trowbridge and Theodore Wm. Richards $\dagger$.}

$\mathrm{N}$ a recent paper upon the spectra of argon $\ddagger$ we have shown 1 that the two different spectra of this gas are dependent primarily upon the electrical conditions which cause the gas to glow. The continuous discharge of a high-tension accumulator through the gas produces the red spectrum, while the discharge of a condenser, provided that its oscillations are

* This was already sufficiently contradicted by the fact that the impression came out enormously stronger on the face turned towards the rathode.

t Communicated by the Authors.

† Suprà, p. 77. 